Discussion Paper No. 968

\title{
POSITIVE AND NEGATIVE EFFECTS OF SOCIAL STATUS ON LONGEVITY: \\ EVIDENCE FROM TWO LITERARY PRIZES \\ IN JAPAN
}

\author{
Shusaku Sasaki \\ Mika Akesaka \\ Hirofumi Kurokawa \\ Fumio Ohtake
}

April 2016

The Institute of Social and Economic Research

Osaka University

6-1 Mihogaoka, Ibaraki, Osaka 567-0047, Japan 


\title{
Positive and Negative Effects of Social Status on Longevity: Evidence from Two Literary Prizes in Japan
}

\author{
Shusaku Sasaki $^{\mathrm{a}}$ Mika Akesaka $^{\mathrm{b}} \quad$ Hirofumi Kurokawa $^{\mathrm{c}}$ Fumio Ohtake $^{\mathrm{d}}$
}

April 13, 2016

\begin{abstract}
We show evidence that receiving Japan's Akutagawa and Naoki Prizes for literature has positive and negative effects on their recipients' longevity. Using a dataset covering both awards, we show that recipients of the Akutagawa Prize for rising novelists exhibit lower mortality than fellow nominees. The increase of longevity is estimated at 2.4 years. Recipients of the Naoki Prize for established novelists exhibit higher mortality than fellow nominees, and the decreased longevity is 5.1 years. These results indicate positive and negative causal effects from social status to longevity, and we identify and isolate those effects. In doing so, this study clarifies why earlier studies show conflicting relationships between receiving awards and the recipients' longevity.
\end{abstract}

Keywords: Social Status, Longevity, Mortality, Cox’s Proportional Hazard Model, Time-dependent Covariates, Time-dependent Parameters

JEL: I12, H14

\footnotetext{
a Graduate School of Economics, Osaka University, and Research Fellow of JSPS

E-mail: ssasaki.econ@gmail.com, Postal Address: Institute of Social and Economic Research,

Osaka University, Mihogaoka 6-1, Ibaraki city, Osaka, Japan, 567-0047

b Graduate School of Economics, Osaka University, and Research Fellow of JSPS

c Graduate School of Economics, Osaka University, and Research Fellow of JSPS

d Institute of Social and Economic Research, Osaka University
}

We thank Yuriko Shiiba, Akihiro Nakajima, Tomoya Nomizo, Jun Kamohara, and Yuta Matsuo for their support in dataset construction. We also thank Naoki Matayoshi, Kanako Nishi, Ryo Kambayashi, Yoshiki Ishikawa, Ayumi Shintani, and participants at the $10^{\text {th }}$ Applied Econometrics Conference 2015 and ABEF's $9^{\text {th }}$ Annual Conference 2015 for discussions, comments, and encouragement.

Our gratitude goes to the Japan Society for the Promotion of Science and the Institute of Social and Economic Research at Osaka University for financial supports. JSPS Grant Numbers are 14J04581(S. Sasaki), 14J07655(M. Akesaka), 13J05272(H. Kurokawa), and (A) 26245041(F. Ohtake). 


\section{Introduction}

It is said that a rise in social status boosts longevity. There are three possible explanations that support this association. First, people with a higher social status generally have higher income, better living conditions, and more access to quality medical care. A rise in social status extends longevity through improved economic conditions. Second, people with a lower social status have monotonous and stressful jobs. In addition, they do not get much emotional or practical support from people close to them (Marmot et al., 1991; Putnam, 2000). A fall in social status shortens longevity through low satisfaction and psychological stress. Third, perceived lower social status induces embarrassment and anxiety. A fall in social status shortens longevity by eroding mental health (Wilkinson, 2000).

Several empirical studies reveal positive correlations between social status and longevity/health (Reid et al., 1974; Marmot et al., 1978; Rose and Marmot, 1981; Marmot et al., 1984; Marmot et al., 1991). Rose and Marmot (1981) used a survey of male civil servants in London to show that men in highly ranked job classifications have relatively low risk of coronary heart disease. However, these results do not demonstrate that causality runs from social status to longevity because reverse causality is possible. In addition, Boyce and Oswald (2012) used a large dataset of British workers to show that workers initially in good health do not become healthier when promoted.

To exploit a causal effect from status to longevity, empirical studies examine datasets of candidates for prestigious prizes, including Academy Awards (Oscars $\left.{ }^{\circledR}\right)$ and Nobel Prizes. Recipients and nominees of distinguished awards plausibly are homogeneous in multiple respects, and thus, being awarded a prize can be viewed as an exogenous shock to social status. Therefore, we can exploit a causal effect from heightened social status to longevity by comparing the life expectancies and mortality rates of recipients and fellow nominees.

Redelmeier and Singh (2001a) show that recipients of Oscars ${ }^{\circledR}$ live 3.9 years longer than Oscar ${ }^{\circledR}$ nominees. In contrast, screenwriters who receive Oscars ${ }^{\circledR}$ live 3.6 years less than their fellow nominees (Redelmeier and Singh, 2001b). Abel and Kruger (2005) show that players inducted into the Baseball Hall of Fame live 5.0 years less than players of similar age. However, Rablen and Oswald (2008) find that Nobel laureates in chemistry and physics live 1.6 years longer than fellow nominees.

Why do studies present these conflicting effects? Sylvestre et al. (2006) and Han et al. (2011) point out that Redelmeier and Singh (2001a) ignore immortal time bias, i.e., they do not consider that actors and actresses who live longer have more opportunities to earn Oscars. To eliminate this bias, Sylvestre et al. (2006) re-estimate Redelmeier and Singh’s (2001a) dataset by fitting a Cox 
proportional hazard model with recipient status as a time-dependent covariate and survival measured from the date of first nomination. They show that the effect of a rise in social status on longevity is positive but statistically insignificant. ${ }^{1}$ When Rablen and Oswald (2008) use a method similar to that of Sylvestre et al. (2006) to address immortal time bias, they show that causality runs from social status to longevity. Differences in how studies address immortal time bias can cause differences in size and directionality of the effects of receiving prizes, but it remains unclear why studies produce conflicting results about the effects of receiving prizes.

To solve this puzzle, we return to the three mechanisms introduced earlier. We suggest that a rise in social status need not boost longevity. First, a positive effect through improved economic conditions can be strengthened when candidates have not obtained stable social status, and this effect weakens as their social status stabilizes. Mirowsky and Hu (1996) empirically show that the size of the effect of higher income on improved physical conditions is larger for lower income levels, and its magnitude diminishes as income rises. In addition, the positive effect of absolute income on utility is larger for lower incomes, and its magnitude diminishes as income rises (Easterlin, 2004; Ohtake et al., 2010). Second, the negative effect of heightened stress can strengthen in some occupations as social status rises. For example, receiving prizes compounds the workloads of novelists, screenwriters, and songwriters, and they struggle to meet diverse needs and deadlines without rest. Redelmeier and Singh (2001b) indicate that a rise in social status shortens longevity of screenwriters nominated for Academy Awards. ${ }^{2}$ In addition, Damaske et al. (2016) collect information regarding stress from 122 employees at multiple time points across consecutive days to show that workers with a higher socio-economic status report greater stress at work and are less likely to meet work demands than those with a lower socio-economic status. Third, a negative effect through erosion in mental health can remain strong after social status rises. Ferrer-i-Carbonell and Frijters (2004) and Ball and Chernova (2008) show empirically that utility, well-being, and happiness are influenced more by relative than absolute socioeconomic conditions. Thus, people with high social status can experience disutility by comparing themselves with neighbors, colleagues, and friends.

\footnotetext{
${ }^{1}$ Smith (2011) notes that no records reveal dates of death for several Hall of Fame inductees, and Abel and Kruger (2005) treated them as still living. After excluding them from the sample, Smith finds that the negative effect from Hall of Fame membership becomes statistically insignificant.

2 The authors attribute the negative effect to differences in occupational characteristics between performers and screenwriters. For example, screenwriters are less compelled to preserve their social image by avoiding disgraceful behavior and maintaining healthy lifestyles. In addition, no following study re-estimates this dataset by addressing immortal time bias. Thus, it remains unclear whether negative causality exists.
} 
We explore two hypotheses. First, positive and negative causal effects run from social status to longevity. If both effects exist, sizes and directionality of the effects of receiving prizes depend on which exerts the larger effect. Second, we can detect the effects on longevity from receiving a prize when candidates occupy an unstable socio-economic status. In that case, the positive effect through improved economic conditions can be strengthened, and it exceeds the negative effects caused by a lack of job control. Conversely, when candidates' socio-economic status is stable, the negative effect prevails. ${ }^{3}$

To test these two hypotheses, we use a dataset of two Japanese literary prizes, the Akutagawa and Naoki Prizes. Testing our hypotheses requires two datasets: one that encompasses lower socio-economic status recipients and nominees and one that encompasses candidates in similar occupations but with higher socio-economic status. Datasets for the two prizes fulfill these requirements. The Akutagawa Prize is awarded to new and promising novelists. Candidates are lowly ranked in an unofficial literary community, Bundan. Also, they generally have low income, vulnerable social network, and a high level of anxiety about their future. In those senses, the candidates are expected to have unstable socio-economic status. In addition, it is awarded for serious literature. Serious literature sells less than popular literature and its books are less frequently published because it is often written in a short story format. Authors who do not receive the prize cannot continue earning income without winning it. In contrast, candidates for the Naoki Prize are recognized novelists and expected to have more stable socio-economic status. Since this prize is for popular literature, they can more easily attain higher economic conditions without receiving it than those for the Akutagawa Prize. We expect empirical results to reveal extended longevity among recipients of the Akutagawa Prize and shorter longevity among recipients of the Naoki Prize.

This paper proceeds as follows. Section 2 explains the two prizes, our dataset, and descriptive results. Section 3 explains econometric strategies. Sections 4 and 5 present estimation results and their interpretation. Section 6 discusses our study's implications and limitations.

\footnotetext{
${ }^{3}$ Previous studies indicate that a positive effect grows among younger candidates. For example, in the dataset of Academy Awards for actors and actresses (Redelmeier and Singh, 2001a), life expectancy is 3.9 years longer for recipients than for fellow nominees. Their median age is 39 . Among the dataset of Nobel laureates, life expectancy is 1.6 years longer for recipients than nominees. Their average age is 51 . It is reasonable to regard the socioeconomic status of younger candidates as less stable. However, we acknowledge systematic differences in candidates' occupations and the nature of these awards.
} 


\section{Data}

\subsection{Overview of Akutagawa and Naoki Prizes}

The Akutagawa and Naoki Prizes share several characteristics. Both were established simultaneously in 1935 by novelist Kan Kikuchi and are sponsored by Bungeishunju Ltd. and the Society for the Promotion of Japanese Literature. Both are awarded twice yearly in January and July, and the $154^{\text {th }}$ awards were presented on January 19, 2016. There have been 1,061 candidates in total, and 344 have received one of the two prizes.

Second, the Akutagawa and Naoki Prizes are Japan's most prestigious literary recognitions, and receiving either delivers an equivalent shock to social status. ${ }^{4}$ Kenzaburo Oe received the $39^{\text {th }}$ Akutagawa Prize in 1958 and the Nobel Prize for literature in 1994. Among novelists awarded the Nobel or said to be candidates, Kobo Abe won the $25^{\text {th }}$ Akutagawa Prize, Shusaku Endo the $33^{\text {rd }}$, and Haruki Murakami was nominated for the $81^{\text {st }}$ and $83^{\text {rd }}$ Akutagawa Prizes. In addition, Yasunari Kawabata, Junichiro Tanizaki, and Yukio Mishima were members of the review committee for Akutagawa Prizes. Works by candidates for the Naoki Prize, including Ryotaro Shiba and Jiro Akagawa, have sold over 100 million copies worldwide, paralleling sales of worldwide best-selling novelists Steven King and Sidney Sheldon. Print, broadcast, and Internet media cover recipients of the Akutagawa and Naoki Prizes.

Third, the two prizes have similar selection procedures. Candidates are selected by 20 members of Bungeishunju Ltd. over a span of 10 meetings. Bungeishunju Ltd. telephones finalists and confirms they have a will to receive a prize if they are awarded it. Recipients are selected by professional novelists on the review committee. Authors can receive either prize only once, but those who have received neither prize can be candidates for both.

However, there are two differences between the Akutagawa and Naoki Prizes. The former is for new or rising novelists, whereas candidates for the latter are established novelists. In addition, the Akutagawa Prize recognizes achievements in serious literature and the Naoki Prize in popular literature, as specified in official introductions written by Bungeishunju Ltd. (2014b).

The latter half of this subsection describes the dataset of the Akutagawa and Naoki Prizes and compares it with datasets in previous studies. First, the Akutagawa and Naoki Prizes are awarded for works published between semiannual awards. Thus, novels appear near the date awards are

\footnotetext{
${ }^{4}$ Recipients receive a pocket watch and prize money. The amount is identical for both prizes, and the relative level does not vary over time.
} 
presented, and social status at publication is similar to social status upon receiving the award. This characteristic is shared by Redelmeier and Singh’s (2001a) dataset of Oscar ${ }^{\circledR}$ nominees.

Second, candidates in our dataset know they are being considered. This means that a causal effect from wining the prizes to longevity includes the discouragement felt by fellow nominees. This characteristic is shared by Redelmeier and Singh’s (2001a) dataset.

Third, our candidates can receive either prize only once. That is not the case among populations in Redelmeier and Singh's (2001a) nor in Rablen and Oswald's (2008) datasets. If candidates can receive the same award multiple times, the analysis must consider that previous recognition might alter covariates for the second award. ${ }^{5}$ Analyzing data for the Akutagawa and Naoki Prizes allows us to ignore influences from these possibilities. In sum, our award-centered dataset parallels that of similar studies while better enabling us to draw causal inferences to longevity.

\subsection{Information Sources of the Dataset}

Our dataset captures recipients' and nominees' names, dates and places of birth, dates and causes of death, educations, side jobs, other prizes received, and books published. We construct this dataset from multiple sources (Table 1). We identify recipients and nominees from records of Bungeishunju Ltd. (2014a) and the home pages of Bungeishunju Ltd. (2014b), “Akutagawa shou no subete, no youna mono” (Kawaguchi, 2015a) and “Naoki shou no subete” (Kawaguchi, 2015b).

We collect information regarding birthdays, dates of death, ${ }^{6}$ places of birth, education, side jobs, and other prizes received ${ }^{7}$ from four biographical dictionaries for Japanese novelists (Shinchosha Publishing Co., Ltd., 1988; Nichigai Associates, Inc., 2002; Nichigai Associates, Inc., 2004; Japan Writers' Association, 2015) ${ }^{8}$ and home pages of literary prizes in Japan. We determine whether

\footnotetext{
${ }^{5}$ Rablen and Oswald (2008) exclude recipients of multiple Nobel Prizes from the sample. Han et al. (2011) use g-estimation to eliminate bias caused by repeat recognition. Robins $(1986,1992)$ and Robins et al. (1992) develop g-estimation to consider immortal time bias and the possibility of a previous win affecting future nomination.

${ }^{6}$ Records for some novelists indicate only the year of birth or death, not their dates, so we insert January 1 as the date. We add a dummy variable that denotes no record for dates of birth or death.

${ }^{7}$ There are public and non-public literary prizes. We consider the following public prizes in Japan: All Yomimono Shinjin, All Yomimono Suiri Shousetsu Shinjin, Asahi Shinjin Bungaku, Asahi Shimbun Kenshou, Bungakukai Shinjin, Bungei, Dazai Osamu, Gunzou Shinjin Bungaku, Shinchou Shinjin, Shousetsu Gendai Shinjin, Shousetsu Subaru Shinjin, Sunday Mainichi Taishu Bungei, Subaru Bungaku, Umitsubame Shinjin Bungaku, and Waseda Bungaku Shinjin. We consider the following non-public prizes: Bungaku, Kawabata Yasunari Sakka, Mishima Yukio, Noma Bungei, Noma Bungei Shinjin, Noma Bungei Shourei, Sakka (Doujin), Shibata Renzaburo, Shinchosha Bungaku, Shinchosha Bungei Dai $1 \mathrm{Bu}$, Shinchosha Bungei Dai 2 Bu, Tanizaki Junichiro, Yamamoto Shugoro, Yoshikawa Eiji Bungaku, and Yoshikawa Eiji Bungaku Shinjin.

${ }^{8}$ When we find insufficient information in these four references, we use the National Diet Library
} 
nominees have received other literary prizes by consulting "Akutagawa shou monogatari" (Kawaguchi, 2013) and "Naoki shou monogatari” (Kawaguchi, 2014). We compile published books from the database of the National Diet Library (2015). We identify causes of death from databases provided by Asahi Shimbun Company (2015), Mainichi Newspapers (2015), and Yomiuri Shimbun (2015).

[Table 1 Here]

\subsection{Descriptive Statistics}

Our analysis uses 708 observations of novelists, among whom 363 (345) are recipients and nominees of the Akutagawa (Naoki) Prize. We exclude from analysis novelists nominated for both prizes, one novelist with a corporate identity, and two nominated in joint name. We exclude novelists for whom dates of birth or death are unavailable. Our analysis covers Japanese male novelists to avoid gender-based and racially based differences in life expectancy.

[Table 2.1 Here]

Table 2.1 shows descriptive results of the outcome variable age at death. It reveals that on average Akutagawa Prize recipients are 6.6 years older at death than their fellow nominees (1\% statistical significance). On average, Naoki Prize recipients are 2.4 years younger than their fellow nominees when they die (10\% statistical significance).

Although the results cannot support causal claims, they can be consistent with the expectation that receiving the Akutagawa Prize has a positive effect on longevity and receiving the Naoki Prize has a negative effect. As introduced in Section 1, our empirical expectations depend on the assumption that candidates for the Akutagawa prize have less stable socio-economic status than those for the Naoki prize. We already supported this assumption by introducing characteristics of the two prizes. We can also confirm it using the information regarding candidates' age, number of published books, side jobs, and other attributes.

[Table 2.2 Here]

and Kawaguchi’s two home pages to complete novelists’ profiles. 
First, we examine candidates' ages when they were nominated and the number of books published by them before nomination. Table 2.2 shows that their average age at final nomination is 37.7 (44.8) for the Akutagawa (Naoki) Prize. At 1\% significance, we can reject the null hypothesis of no difference in ages. Nominees for the Akutagawa Prize are 7.1 years younger than nominees for the Naoki Prize. In addition, the average number of books published is fewer among candidates for the Akutagawa Prize (4.83) than candidates for the Naoki Prize (15.62) at 1\% significance. Younger novelists with fewer publications are more likely to have an unstable socio-economic status.

Next, we consider side employment. Table 2.2 shows two results: (1) the proportion of novelists with no side job or no stable side job ${ }^{9}$ is significantly higher among candidates for the Akutagawa Prize (34\%) than candidates for the Naoki Prize (23\%) at 1\% significance, and (2) the proportion of novelists who are office workers is lower among candidates for the Akutagawa Prize (20\%) than among candidates for the Naoki Prize (34\%) at 1\% significance. These results also support the possibility that candidates for the Akutagawa Prize are more likely to have unstable socio-economic status than those for the Naoki prize.

However, the descriptive results include the possibility of reverse causality that novelists who live longer have more opportunities to be candidates for awards. We should compare the effects of receiving the Akutagawa and Naoki Prizes after statistically dealing with the prospect of reverse causality.

\section{Model}

Following Sylvestre et al. (2006) and Rablen and Oswald (2008), we use Cox's proportional hazard model for the analysis. Its advantages are as follows: (1) we can control for confounding effects by adding covariates, (2) we can address heterogeneity between recipients and nominees before observing them by setting time-zero, (3) we can address heterogeneity between recipients and nominees from the time we start observing them by adding time-varying covariates, and (4) we can consider whether effects of receiving the prizes vary over time by adding time-varying parameters.

Subsection 3.1 explains how we address time-dependency of covariates and parameters of receiving the prizes. The estimation model appears in Subsection 3.2.

\footnotetext{
${ }^{9}$ We define novelists with no stable side job as those who work part-time or frequently change a side job.
} 


\subsection{Time-varying Covariates and Time-varying Parameters}

We consider time-dependency of covariates and time-dependency of parameters from three perspectives. First, to address the possibility that novelists who are destined to live longer have more opportunities for nominations, we set time-zero as the date of first nomination. Second, we address the previously described immortal time bias by adding time-varying covariates to the model. More precisely, we construct the dataset in a panel format capturing first and final nominations. Using a step function, we code novelists as nominees until they receive a prize. We allow as time-varying covariates age and the number of nominations, other prizes received, and published books to vary during the first and final nominations (Simon and Makuch, 1984; Sylvestre et al., 2006; Rablen and Oswald, 2008; Shintani et al., 2009).

[Figure 1 Here]

Third, we address the possibility that effects of receiving prizes vary over time (Kleinbaum and Klein, 2012). To check the time-dependency of parameters of winning, we draw Kaplan-Meier survival functions in Figure 1. Values on the vertical axis are survival rates, and values on the horizontal axis are the number of days between the first nomination and death. We treat as censored samples novelists who are alive at stopping observing, and the novelists who died from non-natural causes.

If the parameters of receiving prizes lack time-dependency, the reduction rates of survival functions among recipients do not vary over time. Figure 1 reveals that the reduction rate among the Akutagawa recipients rises sharply 11,000 days (almost 30 years) after the first nomination. We find no change in reduction rates among Naoki recipients.

[Table 3 Here]

To confirm this finding, we check Akutagawa recipients' survival functions in Table 3. The reduction in their survival function is 0.07 between 7,000 and 11,000 days, 0.28 from 11,000 to 15,000 days, 0.02 from 10,000 to 11,000 days, and 0.10 from 11,000 to 12,000 days. That is, the reduction rate among Akutagawa recipients rises sharply 11,000 days after their first nomination.

In sum, Figure 1 indicates that the parameter for receiving the Akutagawa Prize varies over time. It could change after 30 years following authors' first nomination for the prize. Similar time-dependency is not observed among recipients of the Naoki Prize. 


\subsection{Estimation Model and Variables}

We estimate the following equation:

$$
\begin{aligned}
\lambda(t \mid x)=\lambda_{0}(t) \times & \exp \left(\beta_{1-1} \text { Winner }+\beta_{1-2} \text { Winner } \times(t>11,000)+\beta_{2}\right. \text { Age } \\
& +\beta_{3} \text { Number of Nominations }+\beta_{4} \text { Number of Published Books } \\
& \left.+\beta_{5} \text { Number of Other Prizes }+z^{\prime} \gamma\right)
\end{aligned}
$$

The equation is divided into the baseline hazard of $\boldsymbol{\lambda}_{\mathbf{0}}(\mathbf{t})$ and the regression of $\exp (\ldots)$. In the regression, the treatment variable Winner distinguishes recipients from fellow nominees. We add covariates for age and number of nominations, books published, and other public or non-public prizes received. We also add several attribute covariates, including birth year, winning rate ${ }^{10}$ when nominated, education, information about side jobs, and place of birth.

As explained, we treat novelists as nominees until their prize is actually awarded. We also allow age and number of nominations, other prizes received, and books published to vary between the first and final nominations. In analyzing the Akutagawa Prize, we add Winner $\times(\boldsymbol{t}>11,000)^{11}$ to the regression, considering the time-dependency of the parameter for receiving the prize.

\section{Basic Analysis}

\subsection{Results}

[Table 4 Here]

Table 4 shows results of the survival analysis by a Cox proportional hazard model. We conduct the analysis from datasets for the Akutagawa and Naoki Prizes. We express estimation results in hazard ratios. If the estimated value exceeds 1 , mortality increases, and vice versa. We can read a change in mortality as a percentage by subtracting 1 from the estimated value and multiplying by 100.

This subsection initially presents the estimation results of receiving the prizes and then presents the estimation results of some covariates.

\footnotetext{
${ }^{10}$ We define winning rate as the proportion of winners for nominees in each prize.

${ }^{11}$ We conduct a specification test using the STATA command "linktest," which can detect specification errors in a Cox's proportional hazard model. Test results suggest adding Winner $\times$ $(\boldsymbol{t}>11,000)$ to the model for the Akutagawa Prize but not for the Naoki prize.
} 
Column A1 shows that recipients of the Akutagawa Prize exhibit 62.0\% lower mortality than other nominees until 30 years after the first nomination. After 30 years, their mortality is 4 times higher than the controls. Both effects are statistically significant at $1 \%$.

Column N1 shows that Naoki Prize recipients exhibit 58.4\% higher mortality than fellow nominees. This effect is also statistically significant at $1 \%$. The accompanying columns show these effects are stable after adding a suicide dummy to the model or excluding suicide subjects from the sample.

These results indicate that receiving the Akutagawa Prize has a positive causal effect on longevity during the period within 30 years of the first nomination, and receiving the Naoki Prize has a negative causal effect. However, recipients of the Akutagawa Prize exhibit 4.0 times higher mortality than fellow nominees after 30 years. Thus, we cannot insist that receiving the Akutagawa Prize affirmatively and causally affects longevity during the whole period.

Then we use the predicted values to calculate the expected values for the longevity of each novelist, and we compare them between recipients and fellow nominees. Expected longevity is 48.3 years for recipients of the Akutagawa Prize and 45.9 years for nominees. That is, receiving the Akutagawa Prize extends the longevity of recipients by 2.4 years on average. On the other hand, the expected longevity for Naoki Prize recipients is 34.1 years and for nominees it is 39.2 years. That is, receiving the Naoki Prize shortens recipients' longevity by 5.1 years on average. As a result, we can insist that receiving the Akutagawa Prize exerts a positive causal effect on longevity throughout the period, and receiving the Naoki Prize exerts a negative causal effect.

Next, we present estimation results for age and number of nominations among several covariates. Table 4.1 shows that age and the number of nominations have a statistically significant and stable effect on mortality. Aging increases mortality in both prize datasets. In contrast, the directional effects of the number of nominations differ between the two datasets. Estimation results show that a higher number of nominations increases the mortality of candidates for the Akutagawa Prize but reduces it for those of the Naoki Prize.

\subsection{Interpretations}

Our analysis shows that receiving the Akutagawa prize has a positive causal effect on longevity, whereas receiving the Naoki prize has a negative effect on it. These results are consistent with our empirical estimations introduced in Section 1, i.e., these results confirm our two hypotheses that receiving awards exerts positive and negative effects on longevity and that the net effect depends on the times and situations of receiving the prizes. 
The reasons for these results can be found by considering differences in characteristics between the prizes. We detect a positive effect from receiving the Akutagawa Prize, because it is for new or rising novelists and serious literature, and thus candidates are expected to have unstable socio-economic status. That is, receiving this prize substantially enhances longevity by improving the recipients' economic conditions, and the positive effect exceeds the negative effect because of their increased workloads and lack of job control. We detect a negative causal effect from receiving the Naoki Prize because it is for established novelists producing popular literature, and candidates are expected to have more stable socio-economic status. Therefore, receiving this prize exerts a positive effect on longevity that is less than the negative effect.

Our analysis further shows aging increases mortality in both prize datasets while the directional effects of the number of nominations differ between the two datasets. The former result is intuitive. We can also explain the latter result by surmising that the two prizes generate different degrees of mental shocks from not receiving the awards and from the publicity effects of being nominated. Perhaps mental shock is larger among candidates for the Akutagawa Prize, or the publicity effect is larger among candidates for the Naoki Prize. Receiving the Naoki Prize could be more serious for new or rising novelists. In addition, since established novelists have published more books, being nominated for a prestigious award could boost sales of previous publications.

\section{Further Analysis}

\subsection{Results}

Section 4 established that receiving the Akutagawa Prize has a positive causal effect and receiving the Naoki Prize has a negative causal effect on longevity. We explained that we detect a positive effect from receiving the Akutagawa Prize, because it is awarded to new or rising novelists producing serious literature. We further explained that we detect a negative effect from receiving the Naoki Prize, because it is awarded to established novelists writing popular literature.

Some might argue that receiving the Akutagawa or Naoki Prize produces a differential effect through unobserved factors, including talent and effort, between candidates for the two prizes. If the Akutagawa Prize assembles more talented and earnest candidates and the Naoki Prize assembles less talented and earnest candidates, differences could appear in the effects of receiving the prizes.

However, we found that several novelists nominated for the Akutagawa Prize were nominated or awarded the Naoki Prize. This evidence suggests there is little difference in talent and effort between candidates for the two prizes. We run the second analysis empirically dealing with that 
concern. The second analysis is based on the new assumption that candidates for both prizes are extracted from a common population. More concretely, we combine the datasets of the Akutagawa and Naoki Prizes, assume every candidate can win either prize, and investigate the effect of receiving the Akutagawa or the Naoki Prize. ${ }^{12}$ If the two prizes' candidates constitute different populations defined by unobserved factors, estimation results of receiving the prizes with the combined dataset can be inconsistent with those with each dataset.

When combining datasets, we consider that unsuccessful nominees for the Akutagawa Prize cannot hope to receive it after becoming established authors. However, unsuccessful nominees for the Naoki Prize can expect to receive it later, assuming their standing as established authors does not falter. There are systemic differences between the two prizes in nominees' expectations of being re-nominated and eventually receiving them. To consider that difference, we add to the model a variable denoting endorsements (letters, comments, feedback) of review committees for nominees who did not receive the prize during previous selections. We assume nominees with more endorsements have stronger expectations of receiving the prize eventually. After adding the covariate, candidates for both prizes plausibly become homogeneous (assuming equal talent and effort).

[Table 5 Here]

In Table 5, the model of Column 1 includes the variable that explains the number of letters reviewing nominees for the Naoki Prize only. This variable shows 0 for other candidates. Model 2 includes the variable that explains the number of letters reviewing nominees for both prizes.

The estimation results show that recipients of the Akutagawa Prize exhibit 53.1\%-56.8\% lower mortality than fellow nominees until 30 years after their first nomination. After 30 years, recipients' mortality becomes 3.1-3.2 times higher than that of fellow nominees'. The first (second) effect is statistically significant at 5\% (1\%). Conversely, recipients of the Naoki Prize exhibit 57.3\%-59.0\% higher mortality than fellow nominees. This effect is also statistically significant at $1 \%$. In addition, we reject the null hypothesis that the first effect of receiving the Akutagawa Prize equals that of receiving the Naoki Prize, and we do so for the second effect of receiving the Akutagawa Prize.

\footnotetext{
12 The second analysis adds to the sample 44 new candidates nominated for both prizes. As a result, some won either of the two.
} 


\subsection{Interpretations}

These results coincide with results in Section 4.1. This finding arrests concerns that we detect a positive effect from the Akutagawa Prize and a negative effect from the Naoki Prize because of unobserved factors between candidates for the two prizes. The more reasonable explanation is that the Akutagawa Prize is awarded to rising novelists producing serious literature, and the Naoki Prize is awarded to established novelists writing popular literature.

\section{Conclusion}

This study has demonstrated that recipients of Akutagawa Prizes live 2.4 years longer than authors who were nominated for the prize but did not receive it, and recipients of Naoki Prizes lived 5.1 fewer years than their fellow nominees. These results confirm our hypotheses that receiving awards exerts positive and negative effects on longevity, and that the net effect depends on the times and situations of receiving the prizes. The analysis did not display differences in the magnitude of the effects between the two prizes, and this limitation invites future studies. However, it does demonstrate that the affirmative (negative) effect from receiving the Akutagawa Prize (Naoki Prize) exceeds the negative effect (positive effect).

This study has extended the literature in several ways. First, it suggests why earlier studies show conflicting effects on longevity from receiving awards. Namely, studies showing statistically insignificant correlations between Academy Award winners and longevity (Sylvestre et al., 2006; Han et al., 2011) would yield different results if samples were subdivided into beginning and experienced performers. Second, it refines previous conclusions (Redelmeier and Singh, 2001a) by explaining that findings of negative relationships between awards and longevity are relative- that is, positive and negative effects coexist, but the latter overshadow the former. Third, it introduces a time factor that shows previous findings of an affirmative correlation between longevity and awards (Rablen and Oswald, 2008) are attributable to lags between the dates of achievement and recognition. 


\section{References}

Abel, E. L., and Kruger, M. L. (2005). The Longevity of Baseball Hall of Famers Compared to Other

Players. Death Studies, 29(10), 959-963.

The Asahi Shimbun Company. (2015). Asahi Shimbun Kiji Kensaku "Kikuzou 2 Bijuaru”(The Database of newspapers of the Asahi Shimbun Company). Retrieved from http://database.asahi.com/library2/. (in Japanese)

Ball, R., and Chernova, K. (2008). Absolute Income, Relative Rncome, and Happiness. Social Indicators Research, 88(3), 497-529.

Boyce, C. J., and Oswald, A. J. (2012). Do People Become Healthier after Being Promoted? Health Economics, 21(5), 580-596.

Bungeishunju Ltd. (2014a). Bungeishunju Tokubetsu Henshu Akutagawa Shou Naoki Shou 150kaiZenkiroku (The Record Book of the Akutagawa and Naoki Prizes). Bungeishunju Ltd., Tokyo, Japan. (in Japanese)

Bungeishunju Ltd. (2014b). Kakushou Shoukai (The Introductions of Literary Prizes). Retrieved from http://www.bunshun.co.jp/award/. (in Japanese)

Damaske, S., Zawadzki, M. J., and Smyth, J. M. (2016). Stress at Work: Differential Experiences of High versus Low SES Workers. Social Science and Medicine, 156, 125-133.

Easterlin, R. A. (2005). Diminishing Marginal Utility of Income? Caveat Emptor. Social Indicators Research, 70(3), 243-255.

Ferrer-i-Carbonell, A., and Frijters, P. (2004). How Important is Methodology for the Estimates of the Determinants of Happiness?* The Economic Journal, 114(497), 641-659.

Han, X., Small, D. S., Foster, D. P., and Patel, V. (2011). The Effect of Winning an Oscar Award on Survival: Correcting for Healthy Performer Survivor Bias with a Rank Preserving Structural Accelerated Failure Time Model. The Annals of Applied Statistics, 5(2A), 746-772.

Japan Writers’ Association. (2015). Bungei Nenkan Nihon Bungeika Kyoukai hen (A Biographical Dictionary for Novelists in Japan). Shinchosha Publishing Co., Ltd.,Tokyo, Japan. (in Japanese)

Kawaguchi, N. (2013). Akutagawa Shou Monogatari (The Stories of the Akutagawa Prize). Basilica Co., Ltd., Tokyo, Japan. (in Japanese)

Kawaguchi, N. (2014). Naoki Shou Monogatari (The Stories of the Naoki Prize). Basilica Co., Ltd., Tokyo, Japan. (in Japanese)

Kawaguchi, N. (2015a). Akutagawa Shou no Subete, no youna mono (All about the Akutagawa Prize).Retrieved from http://homepage1.nifty.com/naokiaward/akutagawa/. (in Japanese) 
Kawaguchi, N. (2015a). Naoki Shou no Subet (All about the Naoki Prize).Retrieved from http://homepage1.nifty.com/naokiaward /. (in Japanese)

Kleinbaum, D. G., and Klein, M. (2012). Evaluating the Proportional Hazards Assumption. In Survival analysis (pp. 161-200). Springer New York.

Marmot, M. G., Rose, G., Shipley, M., and Hamilton, P. J. (1978). Employment Grade and Coronary Heart Disease in British Civil Servants. Journal of epidemiology and community health, 32(4), 244-249.

Marmot, M. G., Shipley, M. J., and Rose, G. (1984). Inequalities in Death—Specific Explanations of a General Pattern? The Lancet, 323(8384), 1003-1006.

Marmot, M. G., Stansfeld, S., Patel, C., North, F., Head, J., White, I., Brunner, E., Feeney, A.,and Smith, G. D. (1991). Health Inequalities among British Civil Servants: the Whitehall II Study. The Lancet, 337(8754), 1387-1393.

The Mainichi Newspapers. (2015). Mainichi Shimbun Kensaku "Maiken" (The Database of Newspapers of the Mainichi Newspapers). Retrieved from https://dbs.g-search.or.jp/WMAI/IPCU/WMAI_ipcu_menu.html. (in Japanese)

Mirowsky, J., and Hu, P. N. (1996). Physical Impairment and the Diminishing Effects of Income. Social Forces, 74(3), 1073-1096.

The National Diet Library. (2015). Kokuritsu Kokkai Toshokan Zousho Kensaku Moushikomi Shisutemu (National Diet Library Online Public Access Catalog). Retrieved from http://www.ndl.go.jp/. (in Japanese)

Nichigai Associates, Inc. (2002). Shintei Sakka Shousetsuka Jinmei Jiten (A Biographical Dictionary for Novelists in Japan). Nichigai Associates, Inc.,Tokyo, Japan. (in Japanese)

Nichigai Associates, Inc. (2004). 20 Seiki Nihonjin Jinmei Jiten (A Biographical Dictionary for Japanese People in 20 Century). Nichigai Associates, Inc.,Tokyo, Japan. (in Japanese)

Ohtake, F., Shiraishi, S., and Tsutsui, Y. (2010) Nihon no Koufukudo: Kakusa, Roudou, Kazoku (Happiness in Japan: Disparity, Labor, and Family). Nippon Hyoron Sha Co., Ltd., Tokyo, Japan. (in Japanese)

Putnam, R. D. (2000). Bowling Alone: The Collapse and Revival of American Community. Simon and Schuster, New York, USA.

Rablen, M. D., and Oswald, A. J. (2008). Mortality and Immortality: The Nobel Prize as an Experiment into the Effect of Status upon Longevity. Journal of Health Economics, 27(6), 14621471.

Redelmeier, D. A., and Singh, S. M. (2001a). Survival in Academy Award-Winning Actors and 
Actresses. Annals of Internal Medicine, 134(10), 955-962.

Redelmeier, D. A., and Singh, S. M. (2001b). Longevity of Screenwriters Who Win an Academy Award: longitudinal Study. BMJ: British Medical Journal, 323(7327), 1491.

Reid, D. D., Hamilton, P. J. S., Keen, H., Brett, G. Z., Jarrett, R. J., and Rose, G. (1974). Cardiorespiratory Disease and Diabetes among Middle-aged Male Civil Servants: A Study of Screening and Intervention. The Lancet, 303(7856), 469-473.

Robins, J. (1986). A New Approach to Causal Inference in Mortality Studies with a Sustained Exposure Period-Application to Control of the Healthy Worker Survivor Effect. Mathematical Modelling, 7(9), 1393-1512.

Robins, J. (1992). Estimation of the Time-Dependent Accelerated Failure Time Model in the Presence of Confounding Factors. Biometrika, 79(2), 321-334.

Robins, J. M., Blevins, D., Ritter, G., and Wulfsohn, M. (1992). G-Estimation of the Effect of Prophylaxis Therapy for Pneumocystis carinii Pneumonia on the Survival of AIDS Patients. Epidemiology, 319-336.

Rose, G., and M. G. Marmot (1981). Social Class and Coronary Heart Disease. British Heart Journal, 45(1), 13-19.

Shinchosha Publishing Co., Ltd. (1988). Shinchousha Nihon Bungaku Jiten (A Biographical Dictionary for Novelists in Japan).Shinchosha Publishing Co., Ltd.,Tokyo, Japan. (in Japanese)

Shintani, A. K., Girard, T. D., Arbogast, P. G., Moons, K. G., and Ely, E. W. (2009). Immortal Time Bias in Critical Care Research: Application of Time-Varying Cox Regression for Observational Cohort Studies. Critical Care Medicine, 37(11), 2939.

Simon, R., and Makuch, R. W. (1984). A Non-Parametric Graphical Representation of the Relationship between Survival and the Occurrence of an Event: Application to Responder Versus Non-Responder Bias. Statistics in Medicine, 3(1), 35-44.

Smith, G. (2011). The Baseball Hall of Fame is not the Kiss of Death. Death Studies, 35(10), 949955.

Sylvestre, M. P., Huszti, E., and Hanley, J. A. (2006). Do Oscar Winners Live Longer than Less Successful Peers? A reanalysis of Evidence. Annals of Internal Medicine, 145(5), 361-363.

Wilkinson, R. G. (2001). Mind the Gap: Hierarchies, Health and Human Evolution. Weidenfeld and Nicolson, London, UK.

The Yomiuri Shimbun. (2015). Yomiuri Shimbun Kiji Kensaku "Yomidasu Rekishi Kan" (The Database of Newspapers of the Mainichi Newspapers). Retrieved from https://database.yomiuri.co.jp/rekishikan/. (in Japanese) 


\section{Tables and Figures}

\section{Table 1. Information Sources of the Dataset}

\begin{tabular}{|c|c|}
\hline & Information Sources \\
\hline A List of Winners and Unsuccessful Nominees & $\begin{array}{l}\text { One Record Book Published by Bungeishunju Ltd. (2014a) } \\
\text { The Homepage of Bungeishunju Ltd. (2014b) } \\
\text { The Homepage of "Akutagawa shou no subete, no youna mono" (Kawaguchi, 2015a) } \\
\text { The Homepage of "Naoki shou no subete" (Kawaguchi, 2015b) }\end{array}$ \\
\hline \multicolumn{2}{|l|}{ Birthday } \\
\hline $\begin{array}{l}\text { Date of Death } \\
\text { Place of Birth } \\
\text { Educational Background } \\
\text { Side Job } \\
\text { Other Prizes besides the Two Prizes }\end{array}$ & $\begin{array}{l}\text { Four Biographical Dictionaries for Novelists in Japan (Shinchosha Publishing Co., Ltd., } \\
\text { 1988; Nichigai Associates, Inc., 2002; Nichigai Associates, Inc., 2004; Japan Writers' } \\
\text { Association, 2015) } \\
\text { Homepages of Literary Prizes in Japan }\end{array}$ \\
\hline Published Books & The Database of the National Diet Library in Japan (2015) \\
\hline Cause of Death & $\begin{array}{l}\text { Three Databases of Newspapers (The Asahi Shimbun Company, 2015; The Yomiuri } \\
\text { Shimbun, 2015; The Mainichi Newspapers, 2015) }\end{array}$ \\
\hline
\end{tabular}


Table 2.1. Descriptive Statistics of Age at Death and Death (Dummy)

\begin{tabular}{lcccc}
\hline & \multicolumn{2}{c}{ The Akutagawa Prize } & \multicolumn{2}{c}{ The Naoki Prize } \\
& $\begin{array}{c}\text { Recipients } \\
(\mathrm{N}=109)\end{array}$ & $\begin{array}{c}\text { Fellow Nominees } \\
(\mathrm{N}=254)\end{array}$ & $\begin{array}{c}\text { Recipients } \\
(\mathrm{N}=125)\end{array}$ & $\begin{array}{c}\text { Fellow Nominees } \\
(\mathrm{N}=220)\end{array}$ \\
\hline Mean of Age at Death & $74.42(12.90)$ & $67.83(15.57)$ & $72.48(11.36)$ & $74.89(12.10)$ \\
Mean of Death (Dummy) & $0.49(0.50)$ & $0.50(0.50)$ & $0.56(0.50)$ & $0.59(0.49)$ \\
\hline
\end{tabular}

Table 2.2. Descriptive Statistics of Information Regarding Socioeconomic Status

\begin{tabular}{|c|c|c|c|}
\hline Variable Name & Time & $\begin{array}{l}\text { The Akutagawa Prize } \\
\qquad(\mathrm{N}=363)\end{array}$ & $\begin{array}{l}\text { The Naoki Prize } \\
\qquad(\mathrm{N}=345)\end{array}$ \\
\hline Mean of Age & at First Nomination & $36.33(8.25)$ & $42.52(8.42)$ \\
\hline Mean of Age & at Final Nomination & $37.70(8.56)$ & 44.82 (8.99) \\
\hline Mean of Number of Total Nominations & at Final Nomination & $1.79(1.20)$ & $1.99(1.45)$ \\
\hline Mean of Number of Published Books & at Final Nomination & $4.83(12.86)$ & $15.62(23.30)$ \\
\hline Mean of Number of Other Public Prizes & at Final Nomination & $0.33(0.58)$ & $0.32(0.58)$ \\
\hline Mean of Number of Other Non-public Prizes & at Final Nomination & $0.25(0.46)$ & $0.21(0.50)$ \\
\hline Side Job 1: No Job or No Stable Job & & $0.34(0.48)$ & $0.23(0.42)$ \\
\hline Side Job 2: Creators & & $0.06(0.23)$ & $0.10(0.31)$ \\
\hline Side Job 3: Office Workers & & $0.20(0.40)$ & $0.34(0.47)$ \\
\hline Side Job 4: Self-employed & & $0.18(0.38)$ & $0.19(0.39)$ \\
\hline Side Job 5: Servants & & $0.21(0.41)$ & $0.13(0.34)$ \\
\hline
\end{tabular}

Note: We define novelists with no stable side job as those who work part-time or frequently change a side job. 
Figure 1. Survival Functions for Recipients and Fellow Nominees

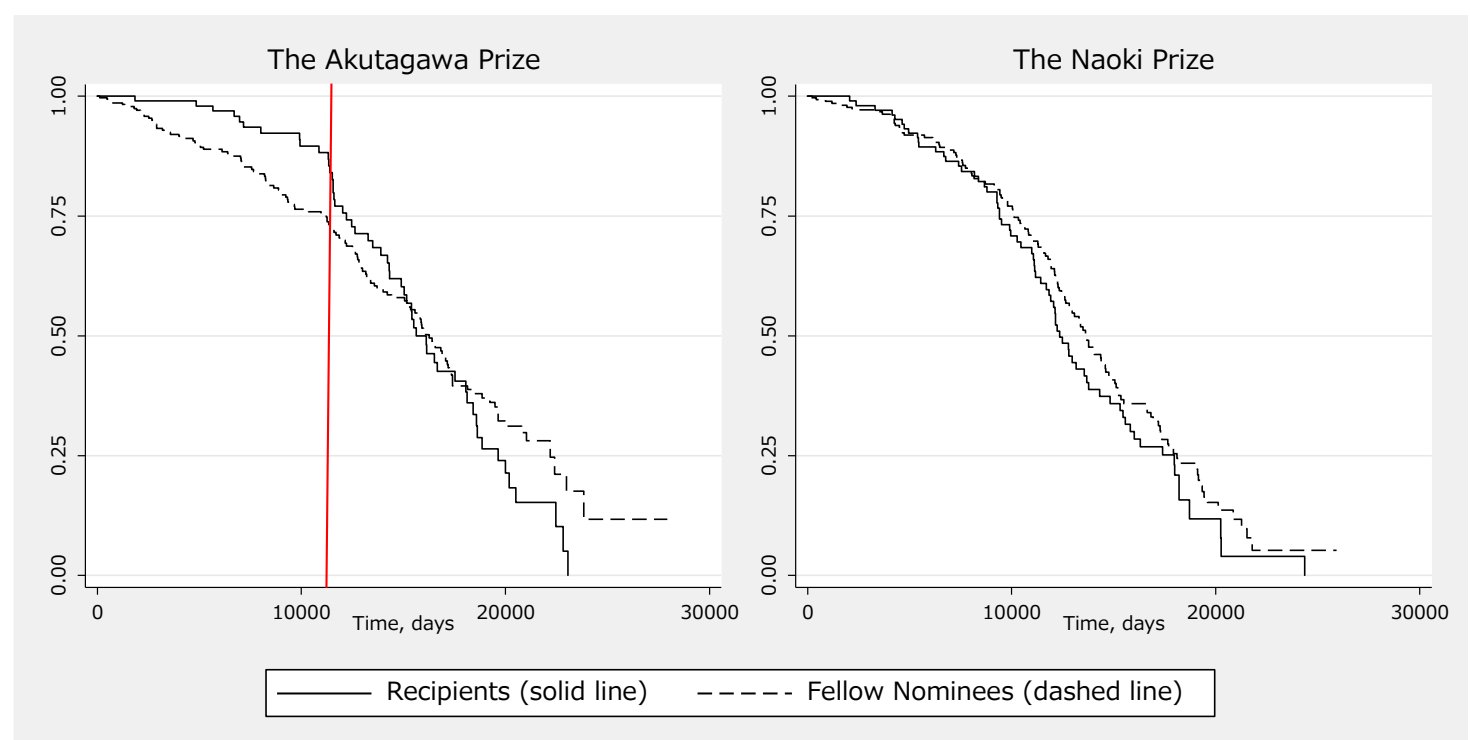

Table 3. Survival Functions for Recipients and Fellow Nominees

\begin{tabular}{|c|c|c|c|c|c|c|c|c|c|c|c|c|c|}
\hline \multicolumn{7}{|c|}{ The Akutagawa Prize } & \multicolumn{7}{|c|}{ The Naoki Prize } \\
\hline Time, days & $\begin{array}{l}\text { Beg. } \\
\text { Total }\end{array}$ & Failures & $\begin{array}{l}\text { Survivor } \\
\text { Function }\end{array}$ & $\begin{array}{l}\text { Std. } \\
\text { Error }\end{array}$ & \multicolumn{2}{|c|}{ [95\% Conf. Int.] } & Time, days & $\begin{array}{l}\text { Beg. } \\
\text { Total }\end{array}$ & Failures & $\begin{array}{l}\text { Survivor } \\
\text { Function }\end{array}$ & $\begin{array}{l}\text { Std. } \\
\text { Error }\end{array}$ & \multicolumn{2}{|c|}{ [95\% Conf. Int.] } \\
\hline \multicolumn{7}{|c|}{ Recipients } & \multicolumn{7}{|c|}{ Recipients } \\
\hline 5000 & 97 & 2 & 0.98 & 0.01 & 0.92 & 0.99 & 5000 & 100 & 8 & 0.92 & 0.03 & 0.85 & 0.96 \\
\hline 6000 & 93 & 1 & 0.97 & 0.02 & 0.91 & 0.99 & 6000 & 94 & 3 & 0.89 & 0.03 & 0.82 & 0.94 \\
\hline 7000 & 84 & 2 & 0.95 & 0.02 & 0.88 & 0.98 & 7000 & 86 & 3 & 0.86 & 0.03 & 0.78 & 0.92 \\
\hline 8000 & 78 & 1 & 0.94 & 0.03 & 0.86 & 0.97 & 8000 & 82 & 2 & 0.84 & 0.04 & 0.76 & 0.90 \\
\hline 9000 & 72 & 1 & 0.92 & 0.03 & 0.84 & 0.96 & 9000 & 73 & 4 & 0.80 & 0.04 & 0.71 & 0.87 \\
\hline 10000 & 68 & 2 & 0.90 & 0.03 & 0.81 & 0.94 & 10000 & 60 & 8 & 0.71 & 0.05 & 0.60 & 0.79 \\
\hline 11000 & 64 & 1 & 0.88 & 0.04 & 0.79 & 0.94 & 11000 & 55 & 3 & 0.67 & 0.05 & 0.57 & 0.76 \\
\hline 12000 & 56 & 8 & 0.77 & 0.05 & 0.66 & 0.85 & 12000 & 47 & 8 & 0.57 & 0.05 & 0.46 & 0.67 \\
\hline 13000 & 50 & 4 & 0.71 & 0.05 & 0.60 & 0.80 & 13000 & 33 & 10 & 0.44 & 0.05 & 0.34 & 0.55 \\
\hline 14000 & 44 & 3 & 0.67 & 0.06 & 0.55 & 0.76 & 14000 & 28 & 4 & 0.39 & 0.05 & 0.28 & 0.49 \\
\hline 15000 & 36 & 4 & 0.60 & 0.06 & 0.48 & 0.71 & 15000 & 26 & 2 & 0.36 & 0.05 & 0.26 & 0.46 \\
\hline \multicolumn{7}{|c|}{ Fellow Nominees } & \multicolumn{7}{|c|}{ Fellow Nominees } \\
\hline 5000 & 202 & 25 & 0.90 & 0.02 & 0.85 & 0.93 & 5000 & 185 & 18 & 0.92 & 0.02 & 0.87 & 0.95 \\
\hline 6000 & 194 & 2 & 0.89 & 0.02 & 0.84 & 0.92 & 6000 & 181 & 1 & 0.91 & 0.02 & 0.87 & 0.94 \\
\hline 7000 & 189 & 3 & 0.88 & 0.02 & 0.83 & 0.91 & 7000 & 168 & 5 & 0.89 & 0.02 & 0.84 & 0.92 \\
\hline 8000 & 177 & 8 & 0.84 & 0.02 & 0.78 & 0.88 & 8000 & 155 & 8 & 0.84 & 0.03 & 0.79 & 0.89 \\
\hline 9000 & 164 & 8 & 0.80 & 0.03 & 0.74 & 0.85 & 9000 & 146 & 5 & 0.82 & 0.03 & 0.76 & 0.86 \\
\hline 10000 & 153 & 7 & 0.76 & 0.03 & 0.70 & 0.82 & 10000 & 133 & 8 & 0.77 & 0.03 & 0.70 & 0.82 \\
\hline 11000 & 142 & 2 & 0.75 & 0.03 & 0.69 & 0.81 & 11000 & 113 & 12 & 0.70 & 0.03 & 0.63 & 0.76 \\
\hline 12000 & 125 & 10 & 0.70 & 0.03 & 0.63 & 0.76 & 12000 & 99 & 9 & 0.64 & 0.04 & 0.56 & 0.71 \\
\hline 13000 & 108 & 10 & 0.64 & 0.03 & 0.57 & 0.70 & 13000 & 80 & 14 & 0.55 & 0.04 & 0.47 & 0.62 \\
\hline 14000 & 97 & 7 & 0.60 & 0.04 & 0.53 & 0.66 & 14000 & 66 & 10 & 0.48 & 0.04 & 0.40 & 0.55 \\
\hline 15000 & 94 & 3 & 0.58 & 0.04 & 0.51 & 0.65 & 15000 & 51 & 9 & 0.41 & 0.04 & 0.33 & 0.49 \\
\hline
\end{tabular}


Table 4. Basic Analysis

\begin{tabular}{|c|c|c|c|c|c|c|c|}
\hline \multirow{2}{*}{\multicolumn{2}{|c|}{$\begin{array}{l}\text { Probability-of-death Equations with Time-varying Covariates } \\
\text { Time-zero: Date of First Nomination }\end{array}$}} & \multicolumn{3}{|c|}{ The Akutagawa Prize } & \multicolumn{3}{|c|}{ The Naoki Prize } \\
\hline & & A1 & A2 & A3 & N1 & N2 & N3 \\
\hline \multirow{10}{*}{$\begin{array}{l}\text { The Akutagawa Prize Winner: } \\
\text { The Naoki Prize Winner: }\end{array}$} & Before 30 Years & $\begin{array}{c}0.380^{* * *} \\
(0.127)\end{array}$ & $\begin{array}{c}0.358^{* * *} \\
(0.118)\end{array}$ & $\begin{array}{c}0.381^{* * *} \\
(0.134)\end{array}$ & & & \\
\hline & After 30 Years & $\begin{array}{c}3.963 * * * \\
(1.525)\end{array}$ & $\begin{array}{c}4.305^{* * * *} \\
(1.642)\end{array}$ & $\begin{array}{c}4.059 * * * \\
(1.625)\end{array}$ & & & \\
\hline & & & & & $\begin{array}{c}1.584 * * * \\
(0.254)\end{array}$ & $\begin{array}{c}1.617 * * * \\
(0.262)\end{array}$ & $\begin{array}{c}1.614^{* * *} * \\
(0.261)\end{array}$ \\
\hline & Age & $\begin{array}{c}1.068^{* * * *} \\
(0.021)\end{array}$ & $\begin{array}{c}1.068^{* * * *} \\
(0.021)\end{array}$ & $\begin{array}{c}1.066 * * * \\
(0.021)\end{array}$ & $\begin{array}{c}1.093 * * * \\
(0.020)\end{array}$ & $\begin{array}{c}1.094 * * * \\
(0.020)\end{array}$ & $\begin{array}{c}1.095^{* * *} \\
(0.020)\end{array}$ \\
\hline & Number of Nominations (Akutagawa) & $\begin{array}{c}1.255^{* * *} \\
(0.090)\end{array}$ & $\begin{array}{c}1.251^{* * *} \\
(0.088)\end{array}$ & $\begin{array}{c}1.229 * * * \\
(0.088)\end{array}$ & & & \\
\hline & Number of Nominations (Naoki) & & & & $\begin{array}{c}0.842 * * * \\
(0.051)\end{array}$ & $\begin{array}{c}0.842 * * * \\
(0.051)\end{array}$ & $\begin{array}{c}0.844^{* * *} \\
(0.051)\end{array}$ \\
\hline & Number of Published Books & $\begin{array}{c}0.989 \\
(0.009)\end{array}$ & $\begin{array}{c}0.989 \\
(0.009)\end{array}$ & $\begin{array}{c}0.990 \\
(0.009)\end{array}$ & $\begin{array}{c}1.002 \\
(0.003)\end{array}$ & $\begin{array}{c}1.002 \\
(0.003)\end{array}$ & $\begin{array}{c}1.002 \\
(0.003)\end{array}$ \\
\hline & Number of Other Non-public Prizes & $\begin{array}{c}0.593 \\
(0.358)\end{array}$ & $\begin{array}{c}0.525 \\
(0.259)\end{array}$ & $\begin{array}{c}0.310^{* *} \\
(0.183)\end{array}$ & $\begin{array}{c}1.295 \\
(0.593)\end{array}$ & $\begin{array}{c}1.216 \\
(0.541)\end{array}$ & $\begin{array}{c}1.160 \\
(0.551)\end{array}$ \\
\hline & Number of Other Public Prizes & $\begin{array}{c}1.648 \\
(1.110)\end{array}$ & $\begin{array}{c}1.875 \\
(1.008)\end{array}$ & $\begin{array}{l}3.186^{*} \\
(1.995)\end{array}$ & $\begin{array}{c}0.756 \\
(0.366)\end{array}$ & $\begin{array}{c}0.788 \\
(0.382)\end{array}$ & $\begin{array}{c}0.819 \\
(0.415)\end{array}$ \\
\hline & Suicide Dummy & & $\begin{array}{c}11.491^{* * *} \\
(4.457)\end{array}$ & & & $\begin{array}{c}13.194 * * * \\
(5.650)\end{array}$ & \\
\hline \multicolumn{2}{|l|}{ Other Attribute Variables: } & IN & IN & IN & IN & IN & IN \\
\hline \multicolumn{2}{|l|}{ Suicide Failures: } & IN & IN & OUT & IN & IN & OUT \\
\hline \multirow{2}{*}{\multicolumn{2}{|c|}{ Number of Subjects: }} & 363 & 363 & 358 & 345 & 345 & 343 \\
\hline & & 1,409 & 1,409 & 1,388 & 1,901 & 1,901 & 1,899 \\
\hline
\end{tabular}

Robust seeform in parentheses, ${ }^{* * *} \mathrm{p}<0.01,{ }^{* *} \mathrm{p}<0.05,{ }^{*} \mathrm{p}<0.1$ 
Table 5. Further Analysis

\begin{tabular}{|c|c|c|c|}
\hline \multicolumn{2}{|c|}{ Probability-of-death Equations with Time-varying Covariates } & \multicolumn{2}{|c|}{ The Akutagawa and Naoki Prizes } \\
\hline Time-zero: Date of First Nomination & & 1 & 2 \\
\hline \multirow[t]{4}{*}{ The Akutagawa Prize Winner: } & Before 30 Years & $0.432 * *$ & $0.469 * *$ \\
\hline & & $(0.142)$ & $(0.157)$ \\
\hline & After 30 Years & $3.080 * * *$ & $3.141^{* * *}$ \\
\hline & & (1.097) & $(1.114)$ \\
\hline \multirow[t]{2}{*}{ The Naoki Prize Winner: } & & $1.590 * * *$ & $1.573^{* * *}$ \\
\hline & & $(0.251)$ & $(0.244)$ \\
\hline \multirow[t]{16}{*}{ Time-varying Covariates: } & Age & $1.075^{* * *}$ & $1.076^{* * *}$ \\
\hline & & $(0.014)$ & $(0.014)$ \\
\hline & Number of Nominations (Akutagawa) & 1.066 & 1.039 \\
\hline & & $(0.058)$ & $(0.056)$ \\
\hline & Number of Nominations (Naoki) & $0.897 * *$ & $0.915^{*}$ \\
\hline & & $(0.043)$ & $(0.044)$ \\
\hline & Number of Published Books & 1.002 & 1.002 \\
\hline & & $(0.003)$ & $(0.003)$ \\
\hline & Number of Other Non-public Prizes & 1.265 & 1.263 \\
\hline & & $(0.439)$ & $(0.440)$ \\
\hline & Number of Other Public Prizes & 0.791 & 0.788 \\
\hline & & $(0.286)$ & $(0.286)$ \\
\hline & Number of Letters in Reviews & $1.023^{* *}$ & \\
\hline & for Fellow Nominees (Only Naoki) & $(0.012)$ & \\
\hline & Number of Letters in Reviews & & $1.016^{*}$ \\
\hline & for Fellow Nominees (Both) & & $(0.009)$ \\
\hline \multicolumn{2}{|l|}{ Other Attribute Variables: } & \multicolumn{2}{|c|}{ IN } \\
\hline \multicolumn{2}{|l|}{ Number of Subjects: } & \multicolumn{2}{|c|}{752} \\
\hline \multicolumn{2}{|l|}{ Number of Observations: } & \multicolumn{2}{|c|}{4,049} \\
\hline
\end{tabular}

Robust seeform in parentheses, ${ }^{* * *} \mathrm{p}<0.01,{ }^{* *} \mathrm{p}<0.05,{ }^{*} \mathrm{p}<0.1$ 